\title{
AL USLUB FII AN NAQD AL BALAGHY
}

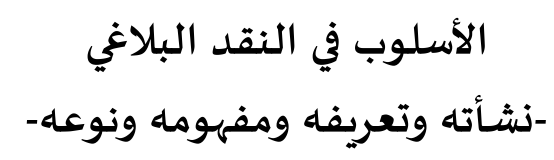

Fitria Fajrina

Khartoum International Institute for Arabic Language, Sudan

Fajrina230293@gmail.com

\begin{abstract}
This study aimed at discovering various uslub used in the Arabic language. The researcher used library research and analyzed it by utilizing the theories of balaghah and analyzing how native speakers use their Arabic. Every language has its way of the technique of structuring words. Moreover, this way of technique means the method or the style used to share one's ideas and feelings so that they reach to their supposed target and could be understood by all the readers or the listeners. So does it what occur in the Arabic language that has various ways of teaching which will not only focus on the shift of reading marks but also on diction, subjects positioning, verbs, or objects those who play a role in making the way if teaching happen. To see a level of Arabic language proficiency, the way one uses uslub with its relevancy to the situation and condition can be seen as one parameter. Furthermore, the discussion on uslub cannot be separated from ilm balaghoh. Ilm balaghoh consists of 3 fields of discussion such as albayan, al maani, and al badi which have interlinked relation with uslub. This is because even each field might have its focus to be discussed, they will still collide in the discussion of uslub.
\end{abstract}

Keywords: Language style; Uslub; Balaghoh; Arabic

\begin{abstract}
Abstrak
Penelitian ini bertujuan untuk menemukan beragam uslub yang terdapat dalam bahasa Arab. Dan peneliti menggunakan metode kajian pustaka dan menganalisisnya dengan memanfaatkan teori- teori yang ada di bidang balaghah juga kebiasaankebiasaan para penutur asli bahasa Arab ketika menggunakan bahasa mereka.

Setiap bahasa memiliki uslub masing- masing, dan makna uslub sendiri adalah cara atau gaya bahasa yang dipakai oleh seseorang untuk menuangkan pokok- pokok pikiran dan perasaannya sehingga dapat mencapai sasaran kalimat yang dikehendaki dan dipahami pembaca atau pendengarnya.

Begitu pula dalam bahasa Arab, bahasa Arab memiliki beragam uslub yang tidak hanya akan berubah pada tanda bacanya saja namun pilihan diksi dan penempatan $\mathrm{fa}^{\prime} \mathrm{il}$, fi'il atau maf'ul pun memilki peran dalam penyusunan sebuah uslub. Tingkat kecakapan berbahasa Arab pun dapat dilihat dari bagaimana penggunaan uslub-uslub yang relevan dengan pendengar serta situasi dan kondisi.

Pembahasan uslub sendiri tidak bisa dipisahkan dengan ilmu balaghah. Bahwasanya ilmu balaghah yang terdiri dari tiga bidang kajiannya yaitu aalbayan, alma'aani, dan al badi' memiliki hubungan yang tidak terpisahkan dengan uslub atau gaya bahasa. Karena hakikatnya, pembahasan ketiga bidang kajian tersebut walaupun memilki
\end{abstract}


pokok- pokok bahasan sendiri, namun pada akhirnya bertemu pada pembahasan tentang gaya bahasa.

\section{Kata kunci: Gaya bahasa; Uslub; Balaghah; Bahasa Arab}

في حين أصبح مصطلح الأسلوبية يطلق على منهج تحليلي للأعمال الأدبية، فالأسلوب

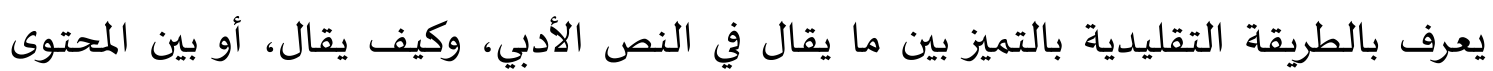
والشكل. وارتبط مصطلح الأسلوب فترة طويلة بمصطلح البلاغة حيث ساعد على تصنيف القواعد المعيارية التى تحملها البالاغة إلى الفكر الأدبي والعالمي منذ عهد الحضارة الإغريقياة، وكتابات أرسطو.

إذن من المعقول والمتوقع أن بتبادر إلى ذهن القارئ المطلّع هذا السؤال، "ماذا عسي

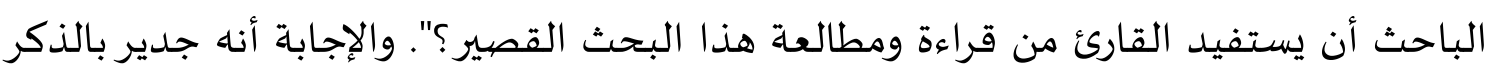
وتجدر الملاحظة أن دراسـات الأسلوب تحتل مكانة متميزة في الدراسات النقدية المعاصرة. إذن فئن سيتناول الباحث موضوع الأسلوب بخاصة وجوده في نقد البلاغة. وتتدرج الكتابة إلى عدة أقسام. والقسم الأول يتحدث الباحث عن نشأة الأسلوب، ويليه يأتي القسم الثاني بتعريفات الأسلوب ومفهوماه من عديد من العلماء، وبعده يتناول البحث نوع الأسلوب وعلاقتاء باللغة

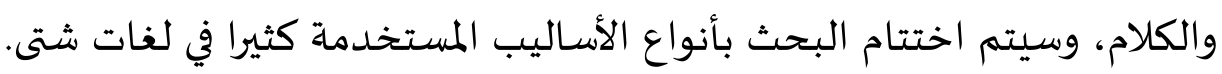
والحمد الله من قبل ومن بعدل وسيتم.

$$
\text { الإطار النطري }
$$

مصطلح الاسلوب Le Style بدأ استعمالها منذ القرن الخامس عشر، على حين لم يظهر مصطلح الاسلوبية stylistique إلا في بداية القرن العشرين كما تدلنا على ذلك المعاجم التاريخية في اللغة الفرنسية مثلا أي أنه خلال القرون من الخامس عشر إلى التاسع عشر كان

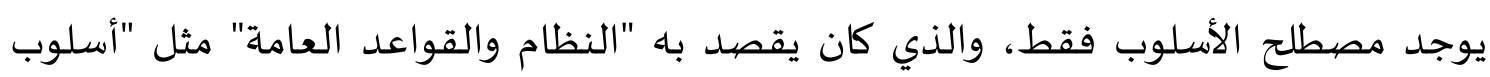
المعيشـة" أو "الأسلوب الموسيقيي" أو "الأسلوب الكلاسيكي في الملبس والاثاث" أو "الأسلوب

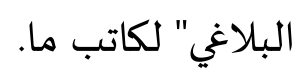

أما في القرن العشرين فقد استمر هذا المصطلح أيضا ولكن وجد على جواره مصطلح آخر هو "الأسلوبية" الذي اقتصر على حقول الدراسـات الأدبية وإن امتد به بعض الدارسين مثل جورج مونان إلى الفنون الجمبلة عامـة. 
قد احتفي العرب منذ القرن الثالث الهجري بدراسة الأسلوب في مباحث الإعجاز

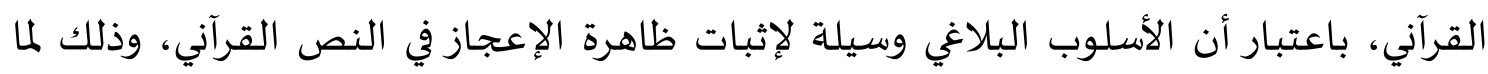

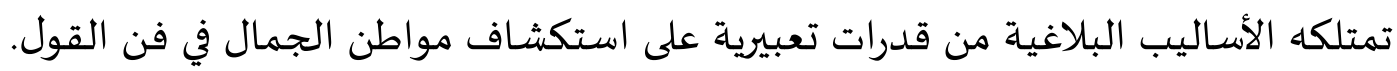

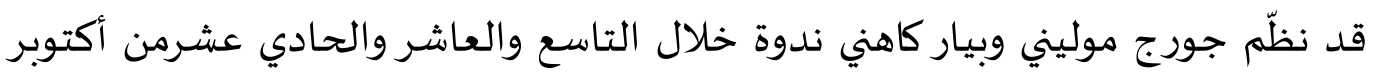

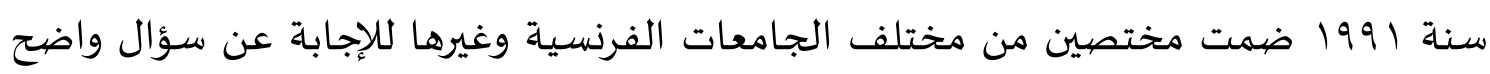
وهو"مالأسلوب؟" غير أن كل مشارك تناول قضية ما من قضيايا الأسلوب والأسلوبية.

\section{ب- تعريف الأسلوب ومفهومه

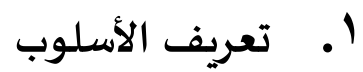

تتناول الدراسات الحديثة مفهوم الأسلوب من زوايا متعددة في محاولة للوصول إلى الى إلى مفهوم محدد، يمكن على أساسه أن تقوم دراسة موسّعة تستوعب أنواع الأداء في مستوياتها

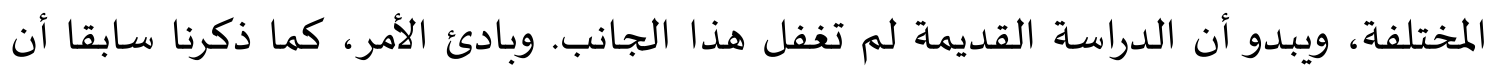

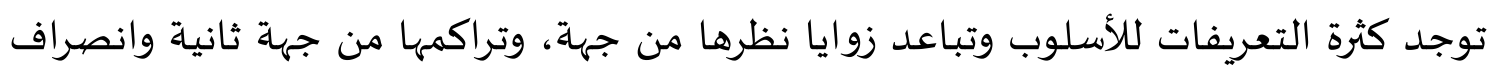

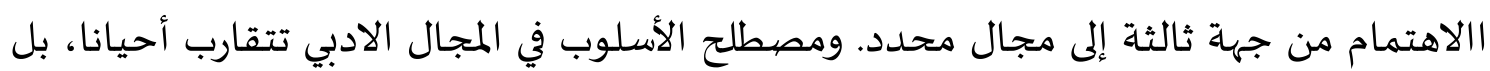

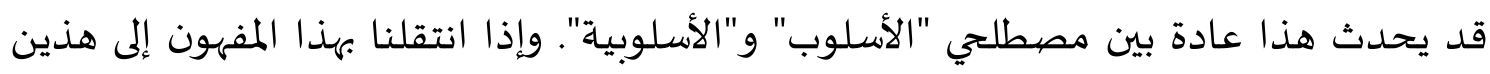

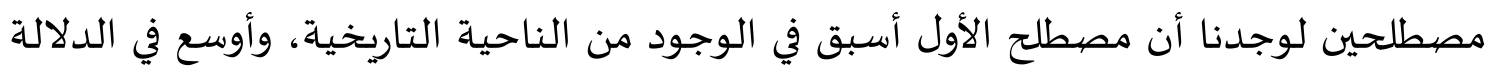
من الناحية المعنوية أي أنه أعم على المستويين الرأسي والأفقي.

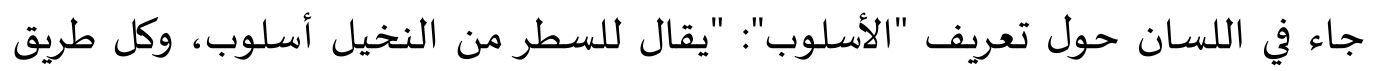

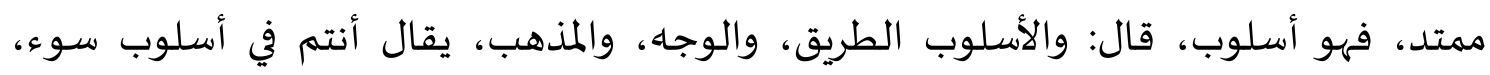

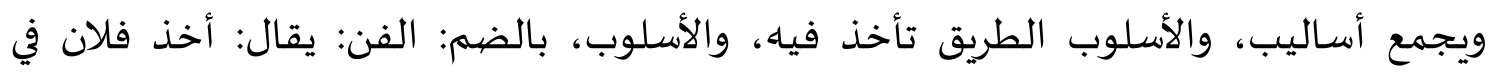

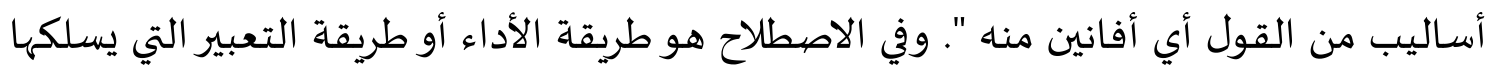

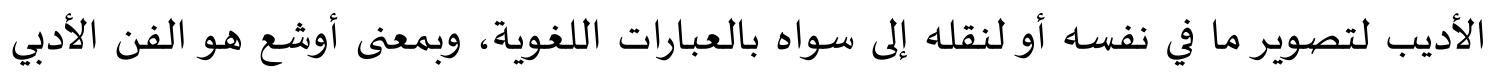

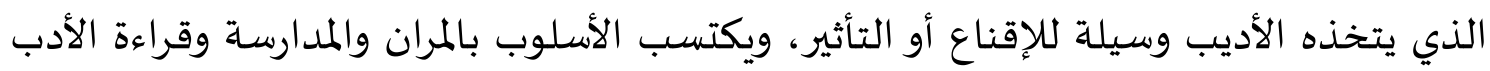

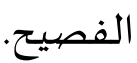

الأسلوب -من كلمة stilus، أي مثقب يستخدم في الكتابة- هو طريقة في الكتابة. وهو

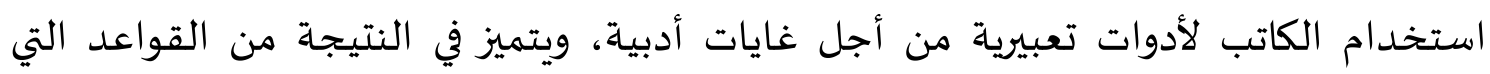
تحدد معنى الأشكال وصوابها. من الملاحظ طرح العلماء تعريفا للأسلوب، إذ يري بوفون ( Buffoon) للأسلوب بأنها

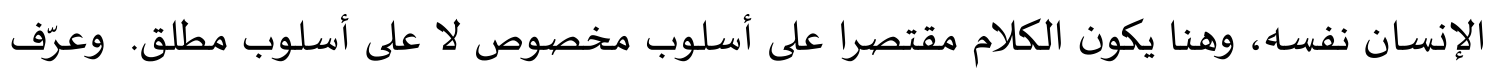


هنري مورير Henri Morier أن الأسلوب تصرف في الوجود، طريقة كيان. ثم قال أيضا غاستون

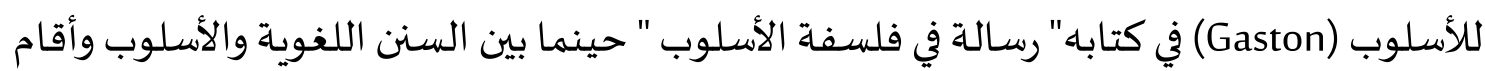

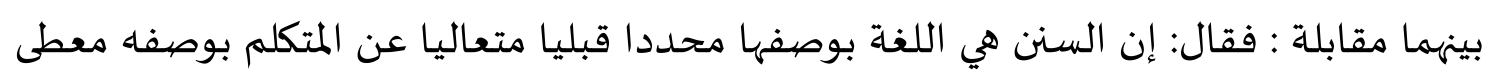
محايدا.

وزبدة القول من هذه الأقوال، قد تعدد مفهوم الأسلوب، فمنهم من يفسر الأسلوب على القان

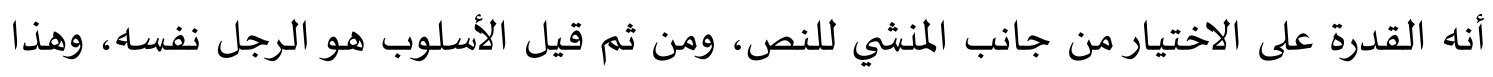

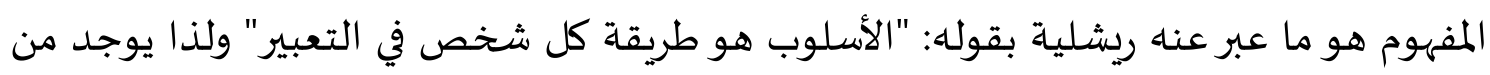

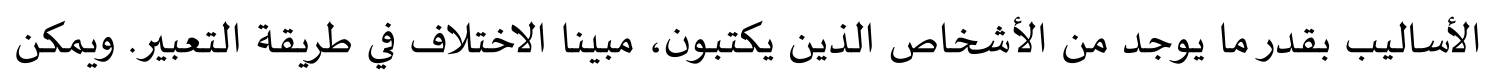
تعريف الأسلوب بانه: النهج اللغوي الذي يشتقه الأديب لنفساء في خضمى المادة اللغوية المتراكمة.

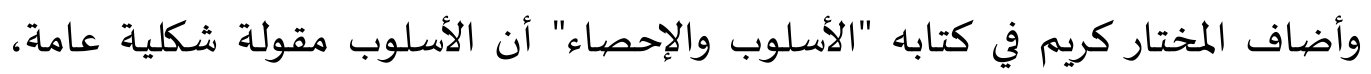

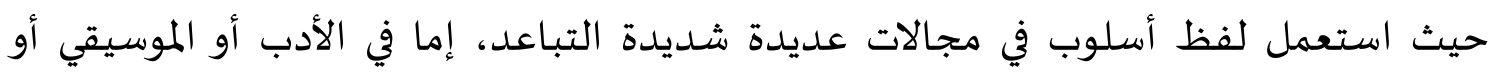

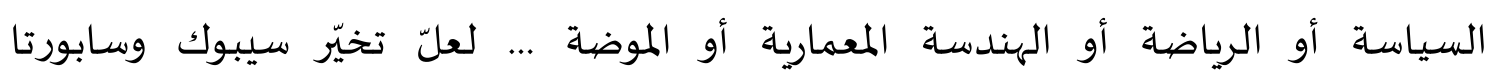

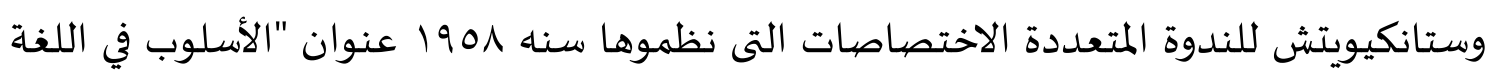

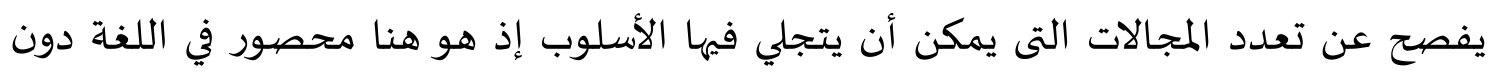

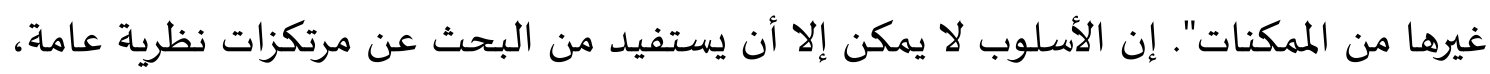

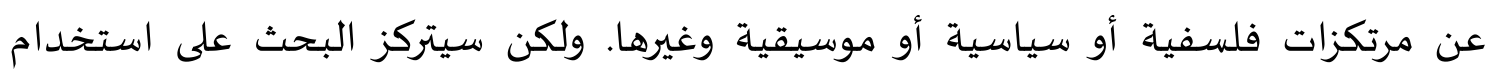
الأسلوب في اللغة خاصية في مجال البلاغة ونقدها.

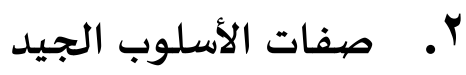

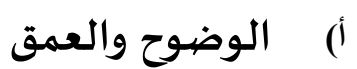

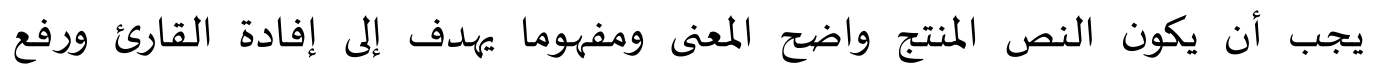

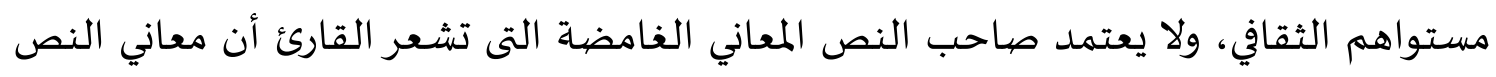

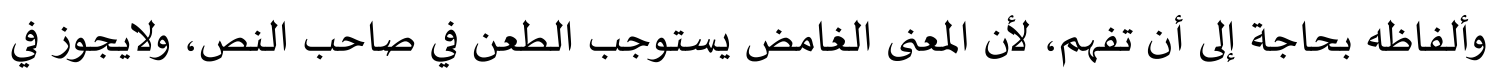

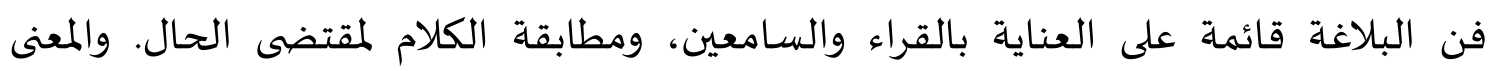

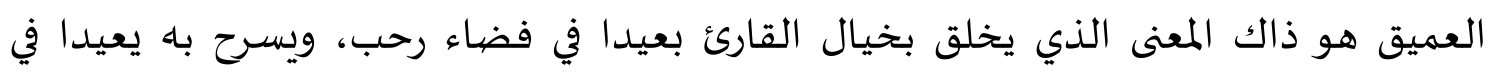

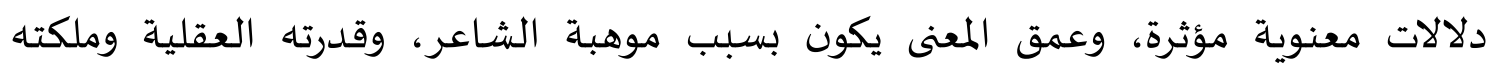

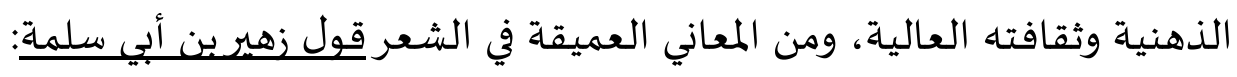

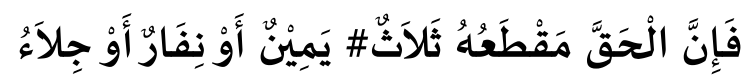

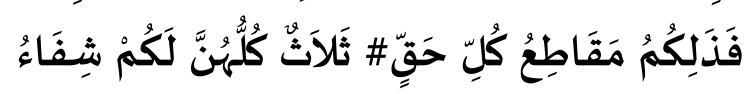


يريد بذلك أن الحق يثبت بواحد من ثلاث: يمين (وهو القسم)، أو محاكمة، أو حجة

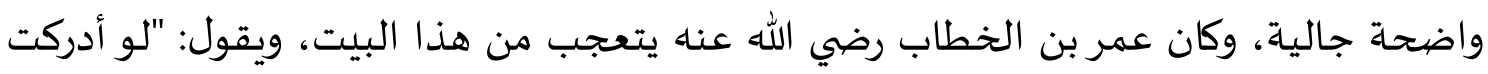

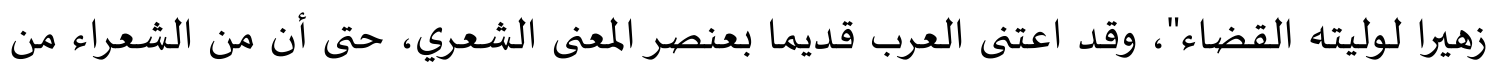

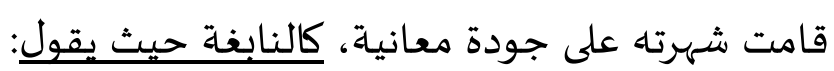

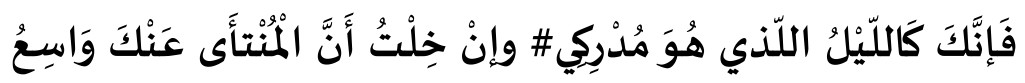

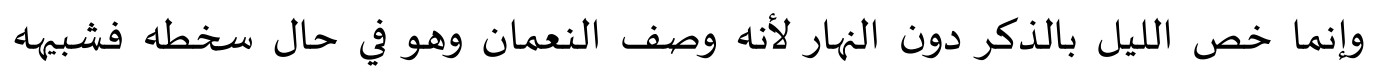

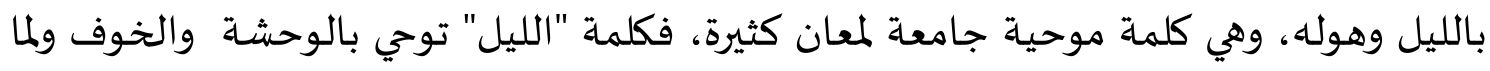

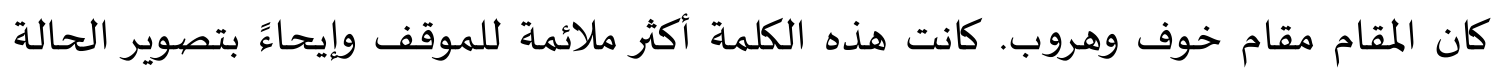

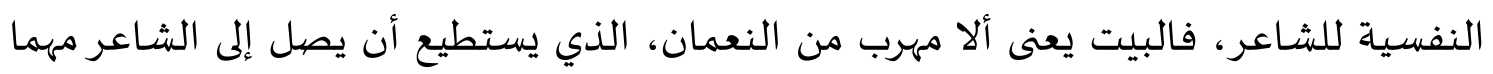

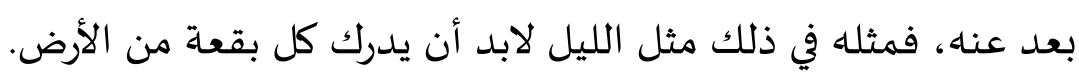

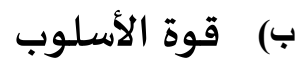
هي صفة نفسية، تتبع من نفس الأديب الذي يجب أن أن يكون متأثرا منفعلا إذا أراد من النا

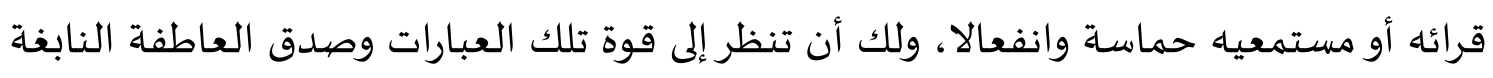

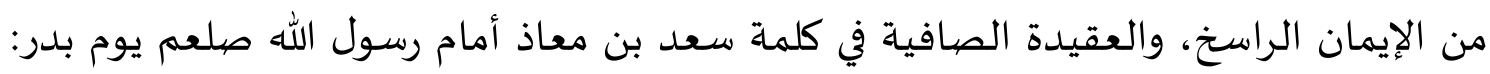

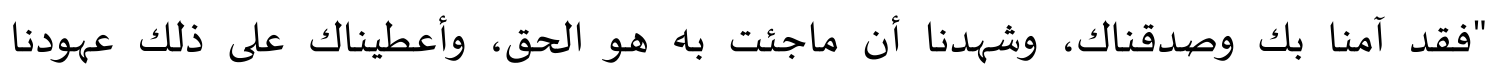

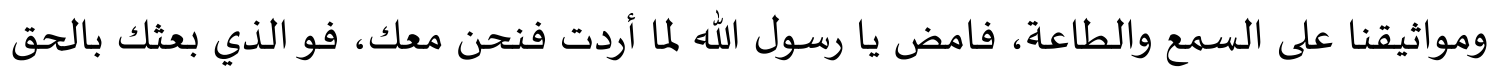

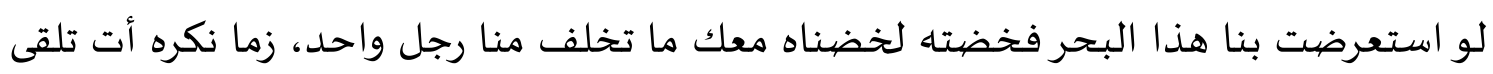

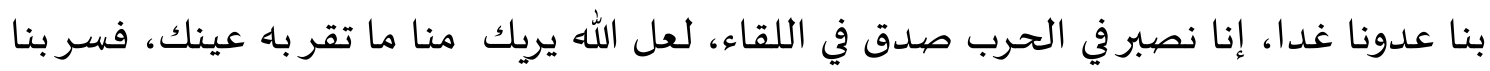

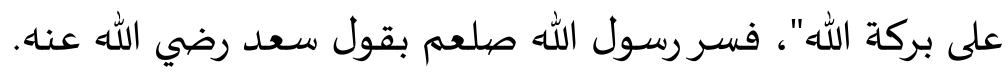

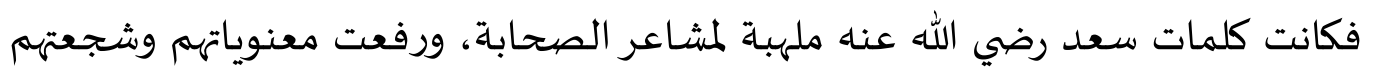

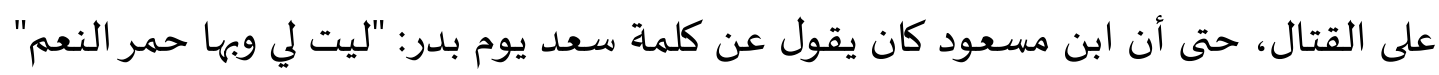

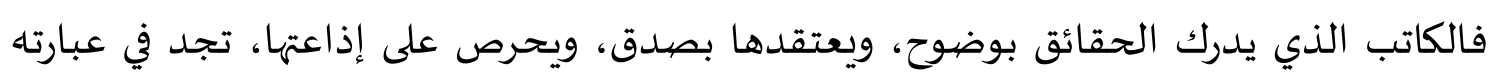

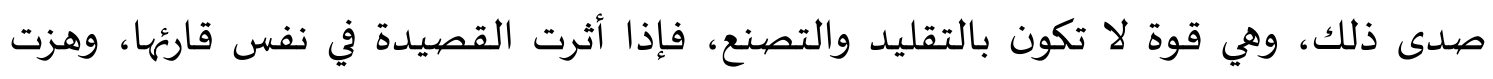

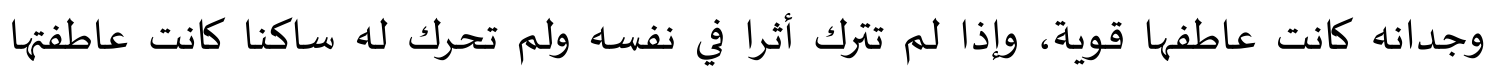

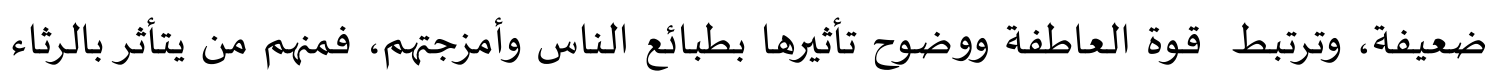

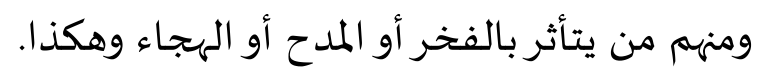

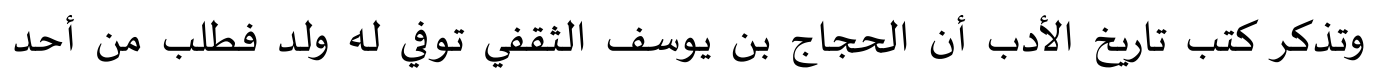

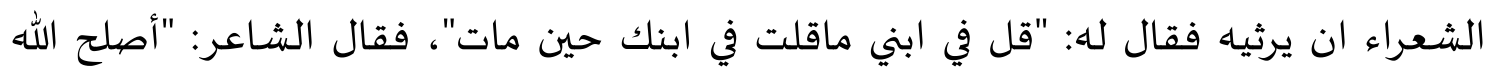

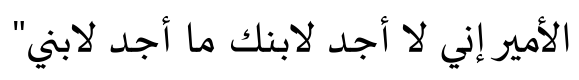


ويقاس صدق عاطفة الشاعر أو كذبه من خلال الدافع الضي دفعه إلى إنتاج عمله

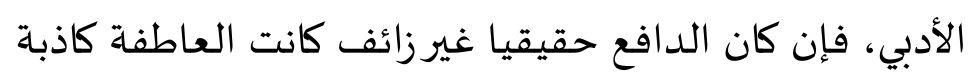

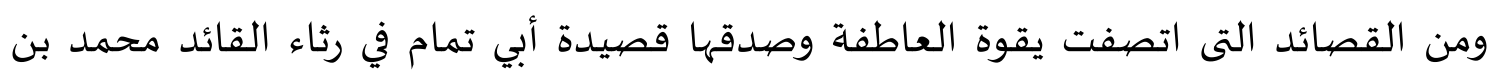

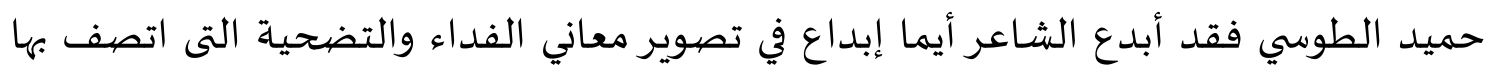
ذلك القائد المسلهم حيث بقول:

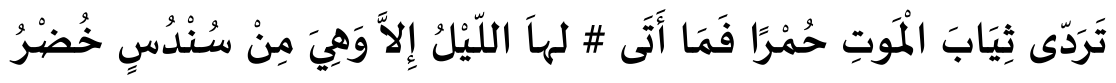

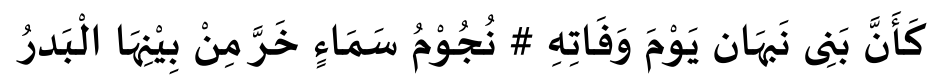

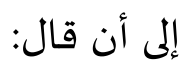

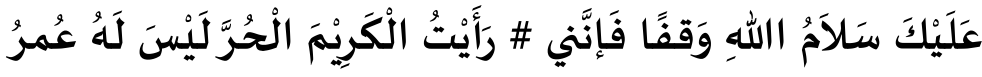

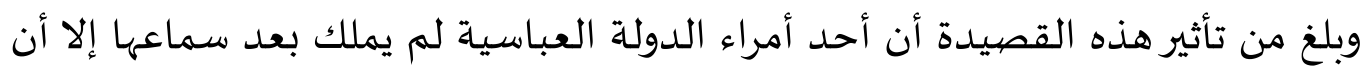

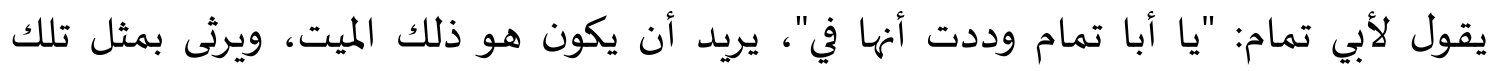

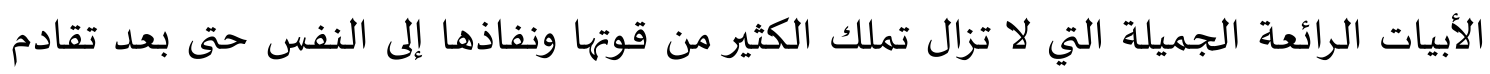

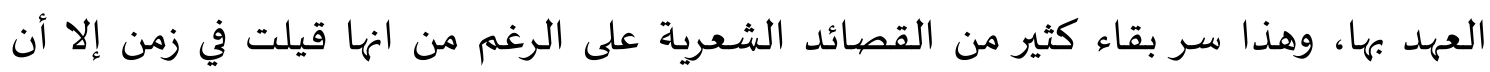

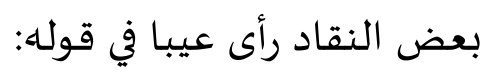

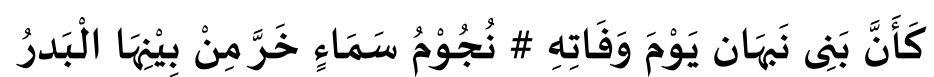

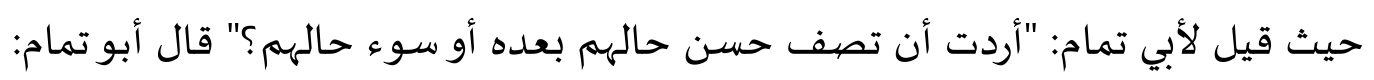

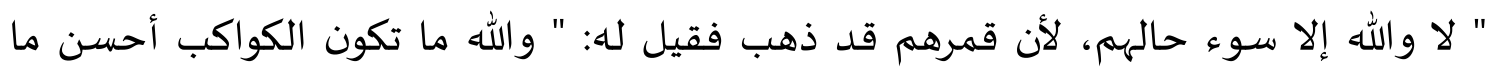

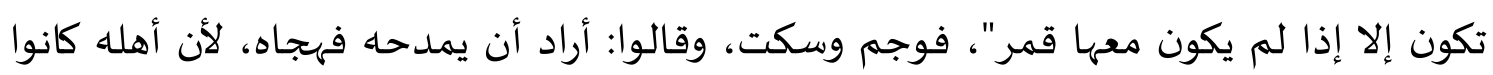
خاملين فلما مات أضاءوا بموته.

$$
\text { ج) جمال الأسلوب ألواته }
$$

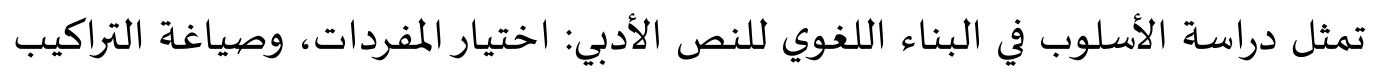

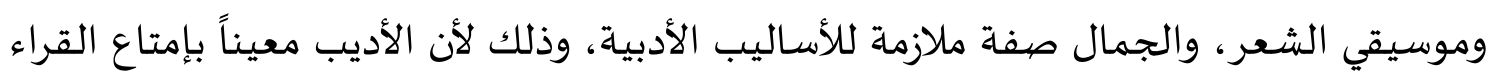

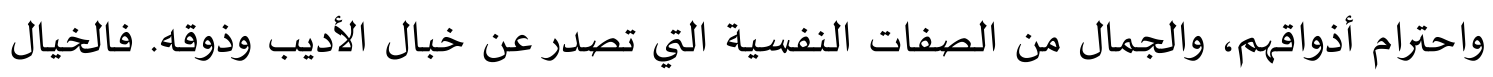

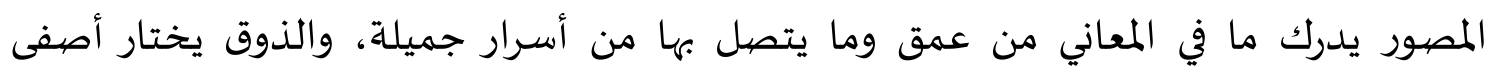
العبارات وألقهيها بهذا الخيال الجميل.

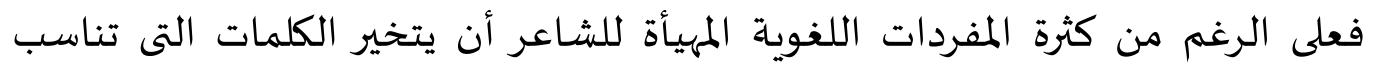

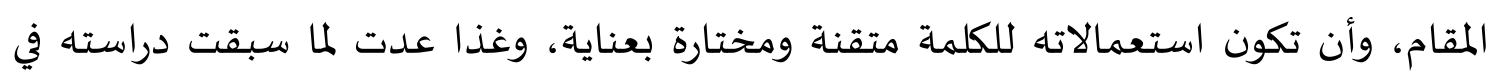

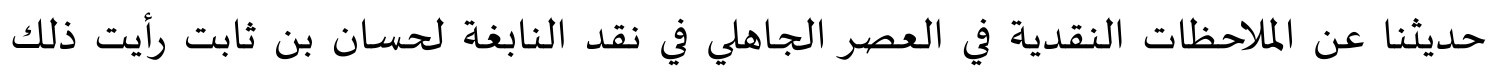


النقد متجها إخفاق الشاعر في دقة اختيار الكلمة ووضعها في موضعها المناسبة، روى أن إبراهيم بن هرمة سمع بيتا له ينشده احد الناس وهو قولهي:

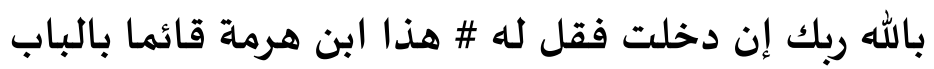

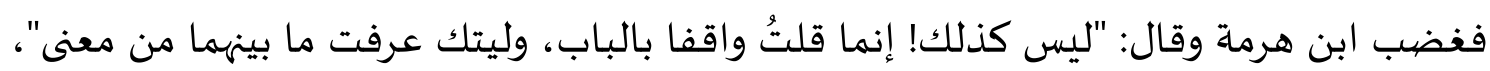

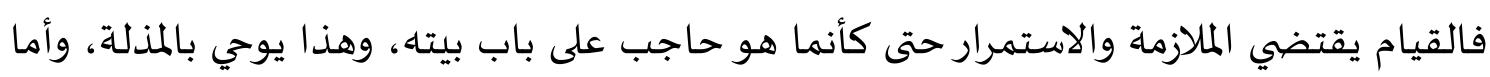
الوقوف فلا يفيد هذا المعنى.

\section{ج- الأسلوب في اللغة}

يتناول قرانجي الأسلوب في اللغة فيبدأ بمشكل الدلالات لا باعتبار أهها مقصودة لذاتها

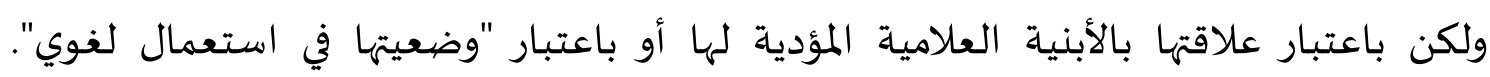

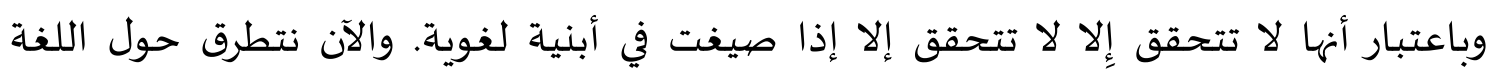

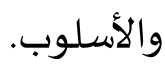

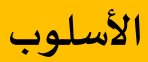

اللغة

ان اللغة مؤسسة اجتماعية وهي نظام كلامي إن الاسلوب مؤسسة خاصة تستمد وجودها من

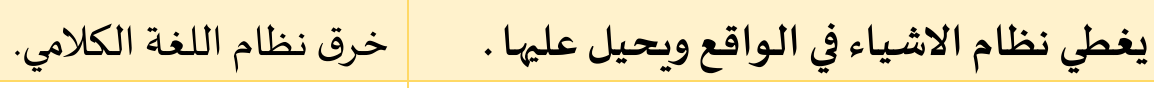

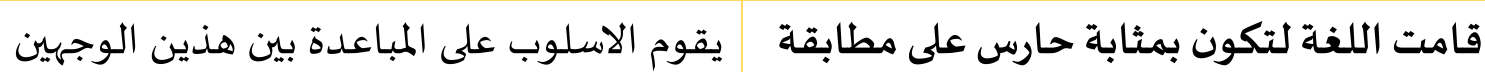
للعلاقة بين الدال والمدلول ومن ثم احداث هوة المباعدة بين هذين العهان كل دال بمدلوله الذي هو له في اصل الوضيع لئي

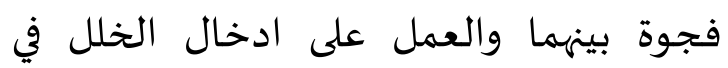
ولكي يبقى كيان العلاقة سليما.

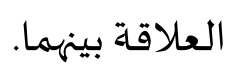

الاسلوب يجسد الذات المتكلمة العاملة في اللغة اللغة عنصر واسع الى درجة يعجز عندها وباللغة. المحلل من ضبطها وتدقيقها

$$
\text { و مثال على ذالك، قال ابو الطيب المتنبي: }
$$

واقبل يمشي في البساط فما درى الى البحر يسعى ام الى البدر البد يرتقي

ومثل هذا يقال عن مدلول لفظة الطفولة في بيت ابي القاسم الشابي-:

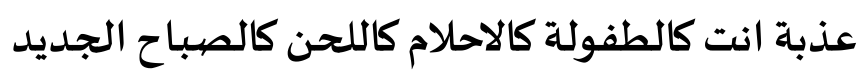

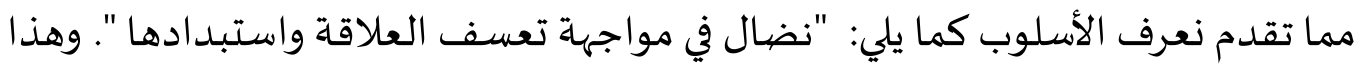

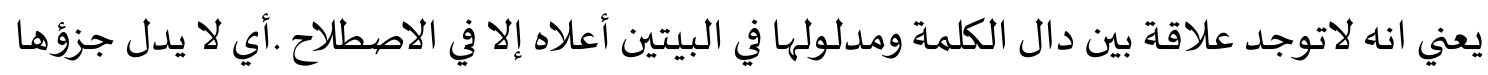

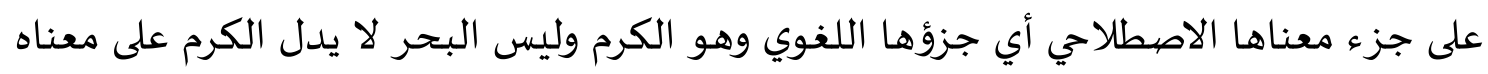


الاصطلاحي وهو البحر. و"الدال" هو الكلمة" والمدلول "هو ما يعبر به عن الكلمة الدال. وهذ

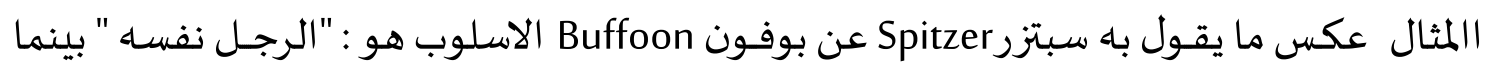

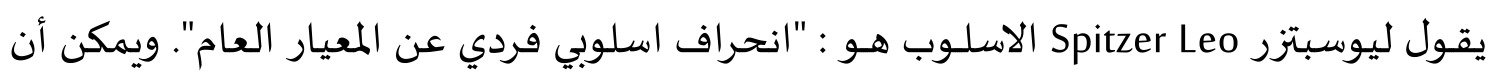

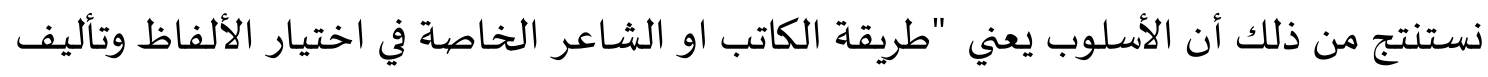

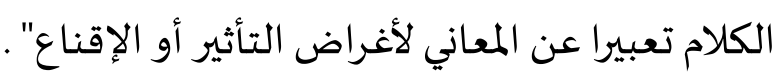

$$
\text { د- أنواع الأسلوب }
$$

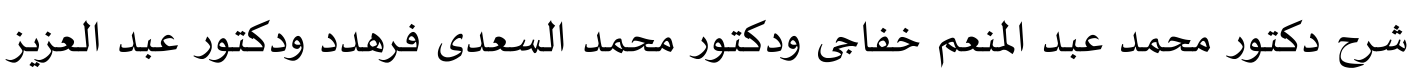

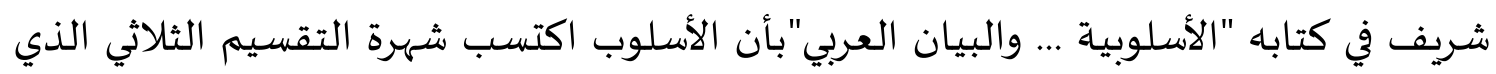

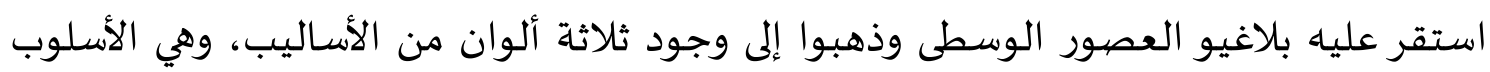

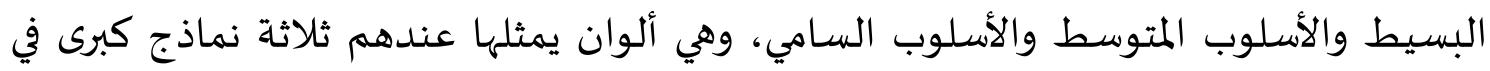

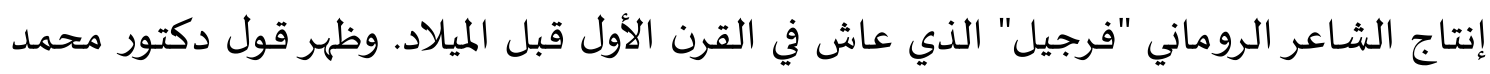

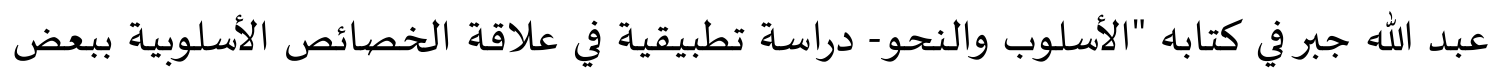

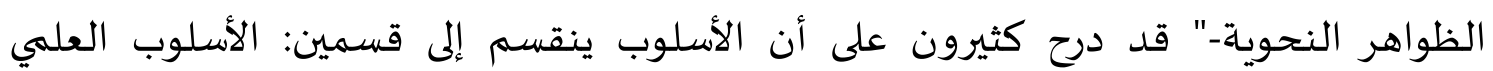

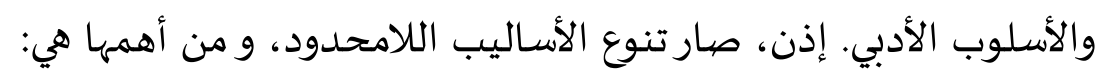

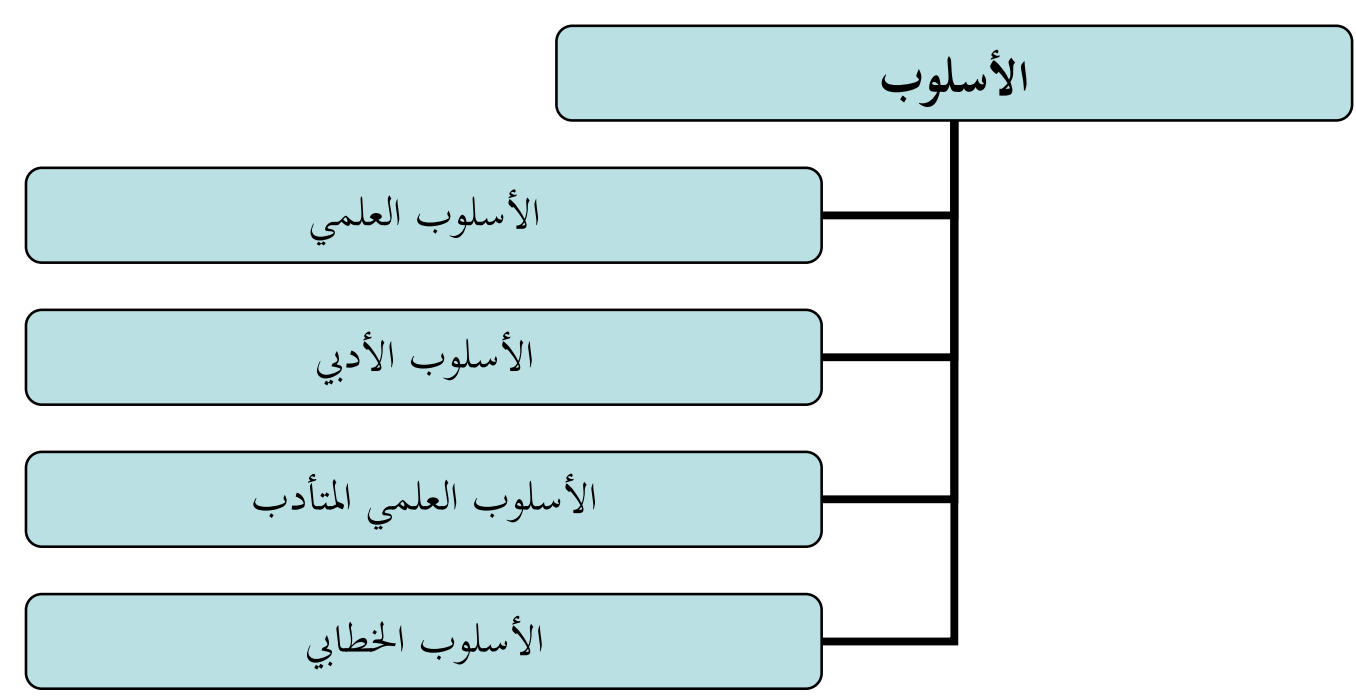




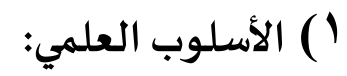

لا شك في أنك تدرك الفرق الواضح بين أساليب الشعر وأساليب النثر التي ندرسها ويقصد بالأسلوب العلمي ذلك الأسلوب الذي يستخدم في صوغ العلوم المجردة، كالطب، الهندسـة،

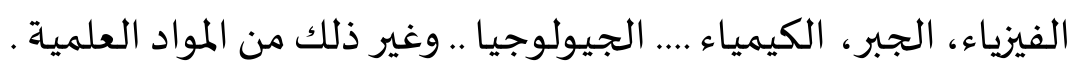
أي أنه : الأسلوب الذي يعبر باء العلماء عن الموضيوعات والقضيايا العلمية البحتة.

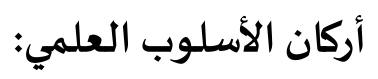

بتحليل أي نص علمي نجده يتكون من الركنين الأسـاسيين للأسلوب وهما : الأفكار والمعاني +الكلمات والجمل والصياغة . ذلك لأن الأسلوب العلمي يقصيد فقط إلي نقل الحقائق العلمية مجردة ، بقصد الإفهاموالإقناع.

$$
\text { نموذج الأسلوب العلمي : }
$$

في تعليل سبب صرخة المولود التي يطلقها عند ولادته ، تعليلاً علمياً طبياً قبل : تعد صرخة الحياة التي يطلقها المولود عند ولادته، من الحركات غير الإرادية التي تحدث للوليد،

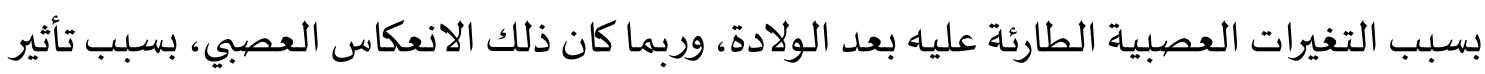

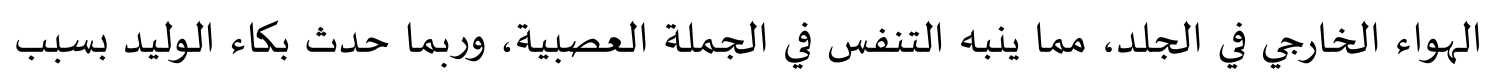
انقطاع الدوران الجنيني الشيهي، مما يستدعي تراكم حمض الفحم في الدم، وتنبه مراكز التنفس ، فتتقلص عضلات الصدر ، ويحدث الشهيق ، ويتبعه الزفير.

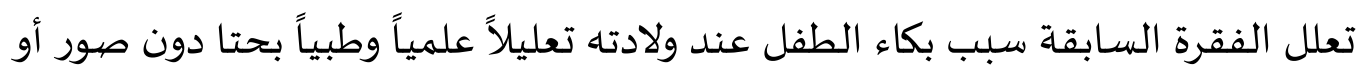
وجود أ شيء من الإحساس بالعاطفة والانفعال ، إنما فقط فهمنا بالرأي العلمي أسباب هذا البكاء. هذا من حيث المعني الذي نقل إعن إلينا.

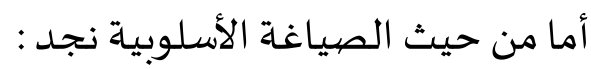
أ) أهها حافلة بالمصطلحات العلمية والطبية المحددة ، مثل: الانعكاس العصبي ، مراكز التنفس ، ب) الجملة العصبية، الدوران الجنيني ، حمض الفحم ، الشهيق ، الزفير .

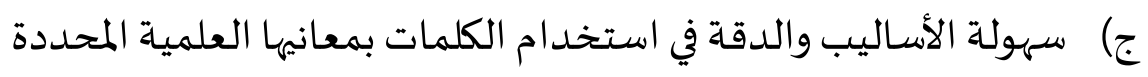
د) عدم وجود صهور خيالية ، أو ألوان بلاغية .

ومن هنا نعرف أن خصائص الأسلوب العلمي قد تكون في موضوعاته علمية بحتة، والأفكار فيه واضحة ومحددة، وتستخدم فيه الأرقام والمصطلحات العلمية، ودقة استخدام 
الألفاظ وتحديد دلالتها، ويخلو من استخدام الصور الخيالية اولمحسنات البلاغية والعاطفة أو الشعور. ولا تظهر فيه شخصية صاحبه أو آراؤه، ويخاطب العقل بقصيد الإفهام والإقناع، ويهدف إلي توصيل الحقائق العلمياة ، وأسلوباه حقيقي تقريري ولا يحتمل الأغراض البلاغية التي عرفناها في علم المعاني، ويمتاز بترتيب الأفكار وتسلسل المعاني. والأسلوب العلمي يخاطب طبقة خاصية في مجاله.

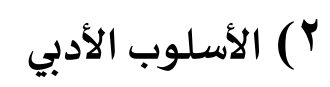

إذا عرفنا أن الأدب هو كل إنتاج جيد من الشعر أو النثر، فما المراد الأسلوب الأدبي وما

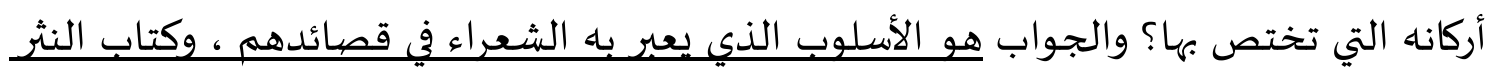
الفني في الخطب والرسائل الإخوانية. والمقال الذاتي ، والقصص والمسيرحيات.

$$
\text { أركان الأسلوب الأدبي: }
$$$$
\text { نموذج الأسلوب الأدبي من الشعر : }
$$

قال ابن الرومي في بكاء الطفل عند ولادته: لما تؤذن الدنيا من صروفها يكون بكاء الطفل سـاعة يولد

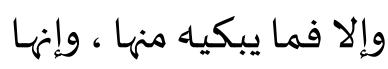

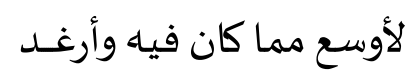
إذا أبصر الدنيا استهل كأنه بما سوف يلقي من أذاها يهدد تتمثل في الأبيات كل عناصر الأسلوب الأدبي وخصائصيا: 


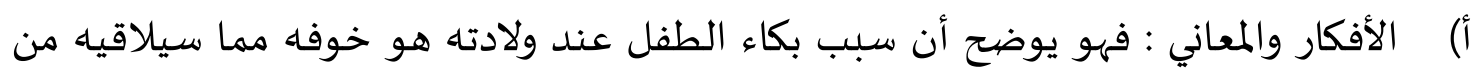

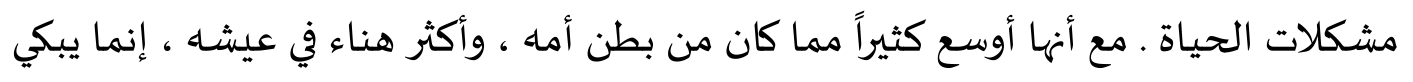

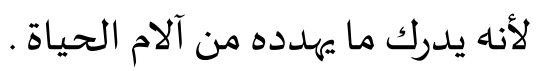

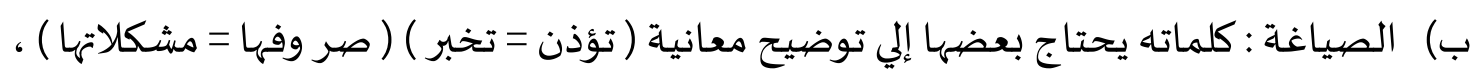

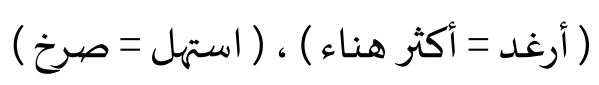

ج) الصور الخيالية : في الأبيات بعض الصتل الصور الخيالية مثل" تؤذن الدنيا " (استعارة مكنية )، يلقي من أذاها= استعارة أيضا .

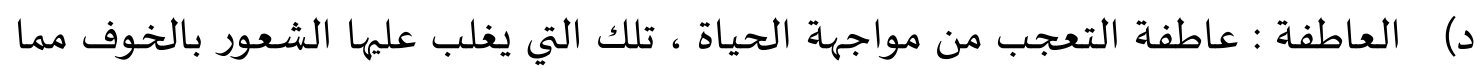
ينتظر المولود

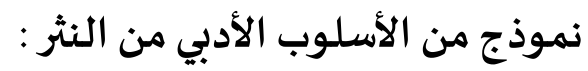

من كتاب الأدب والنصوص فالأول من خطبة الحرب للمنفلوطي حيث قال :

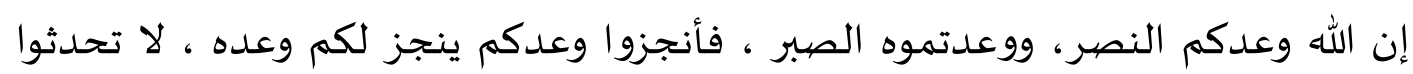
أنفسكم بالفرار ، فو الله إن فررتم لا تفرون إلا عن عرض لا يجد إند حاميا ، وشرف لا لا يجد له له

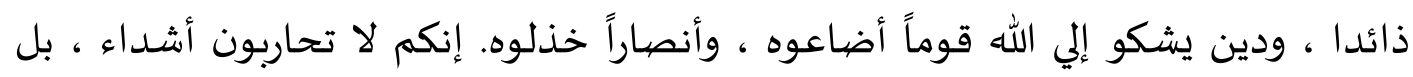

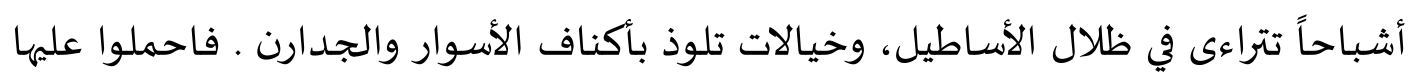

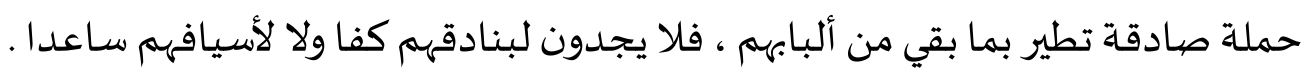

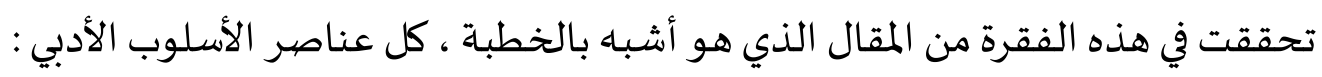

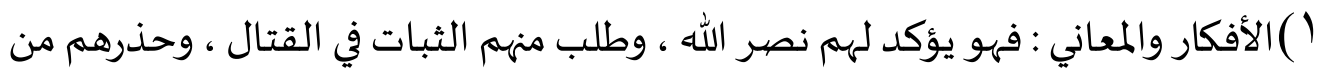

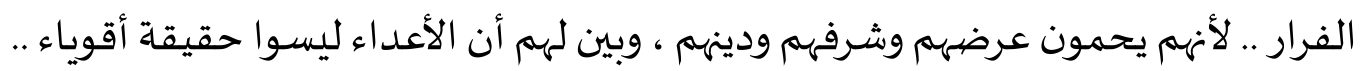

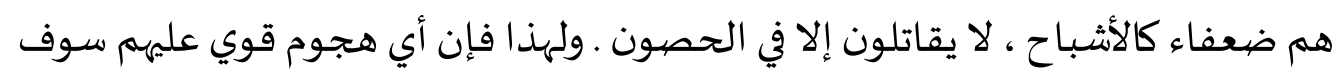
يشتت شملهم ، ويقضي على قدرتهم ، فلا يستطعون دفاعا .

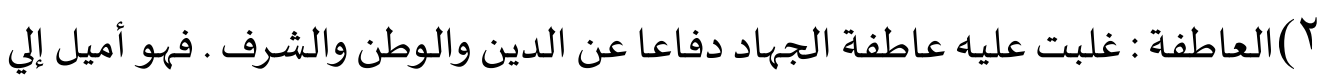

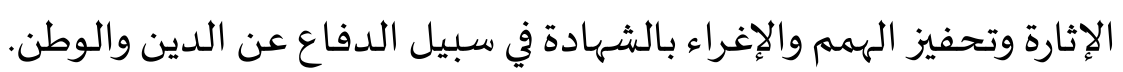

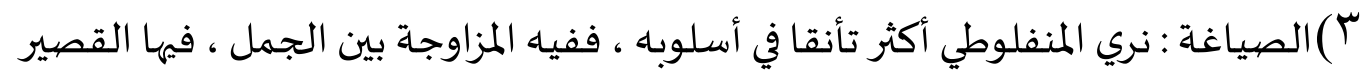

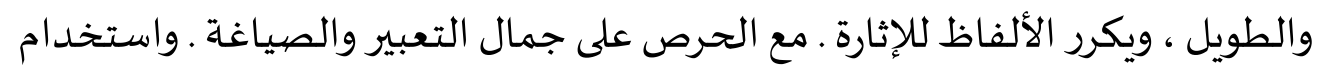

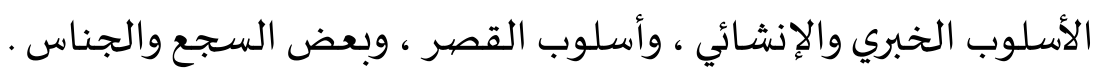
ع) الصور الخيالية : جاءت في الفقرة بعض الصور الخيالية ، منها : دين يشكو إلي الله ( استعارة مكنية) 
(ب) تحاربون أشباحاً (تشبياء للأعداء في ضعفهم بالأشباح)

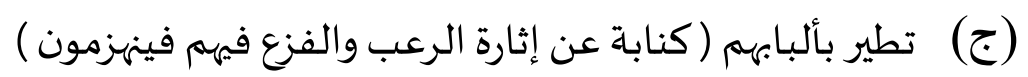

ومن هنا خصائص الأسلوب الأدبي قد تكون في أن يتحدث عن موضوعات ليست ذات طابع علمي بحت، و يخلو من الأرقام والمصطلحات والإحصاءات العلمية ، وفياه دقة اختيار الألفاظ والتأنق في الأسلوب اوستخدام الصيور الخيالية والمحسنات البلاغية . ويختص الأسلوب الأدبي ظهور عاطفة الكاتب أو الشـاعر بوضوح وشخصياة صاحباه وآراؤه وثقافته. ثم يهدف إلي إثارة القارئ وإمتاعه .

الفرق بين الأسلوبين

أـ الأسلوب العلمي ينعدم فيه الخيال والعاطفة وتكثر فيه المصطلحات - بينما الأسلوب

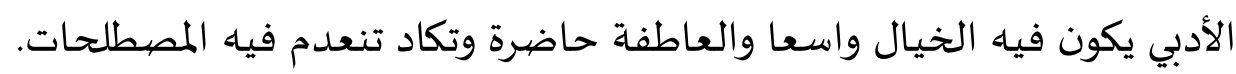

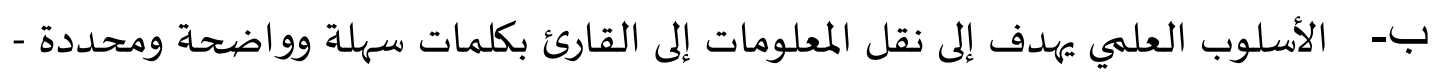
بينما يهدف الأسلوب الأدبي إلى الإمتاع والمعرفة مستخدما تراكيب جميلة وألفاظا موحية ورقيقة أو قوياة.

ج- الأسلوب العلمي يخاطب العاطفة والوجدان ولهذا فالغرض منه إثارة الانفعال في نفوس القراء والسـامعين، وبهذا يجمع الأسلوب الأدبي بين الغفادة والتأثير

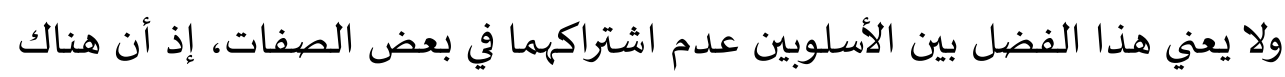

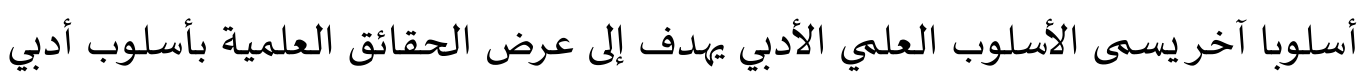
جميل، ولكن هذا الأسلوب محدود الانتشار.

\section{ب) الأسلوب العلمي المتأدب}

إذا كان الأسلوب العلمي محدد المعاني، خاليا من العاطفة والخيال والبلاغة لأن هدفه الإفهام والإقناع. وإذا كان الأسلوب الأدبي حافلا بالعاطفة محشوا بالخيال، قائماً على الأساليب

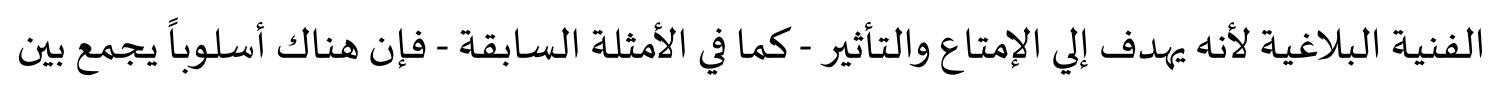
الحسنيين، يجمع بين أهداف الأسلوب العلمي في عرض الحقائق العلمية ويقصد إلي الإفهام

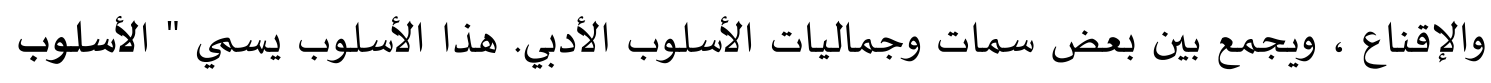
العلمي المتأدب " وهو المتمثل في النصوص العلمية التي تكتسب قيمة أدبية من طريقة عرضهيا، وعلى رأس هذا النوع كتب التاريخ وكتب الرحلات. فمن مؤلفيها من يمتعون القارئ بطريقتهم في سرد الأحداث، ووصف المناظر، وتقديم الشخصيات، وتحليل الدوافع الإنسانية . حتى لتحسب أنك فئك 
تقرأ قصة خيالية لاعرضا علمياً. إنه أسلوب يقدم لنا الحقائق العلمية في أسلوب يقربها إلينا وتخفيف جفافها باستخدام الأسلوب الأدبي الجميل .

$$
\begin{array}{r}
\text { أركان الأسلوب العلمي المتأدب ) } \\
\text { الأفكار والمعاني ) الصياغاة } \\
\text { ( بعض جماليات الأسلوب الأدبي }
\end{array}
$$$$
\text { نموذج للأسلوب العلمي المتأدب }
$$

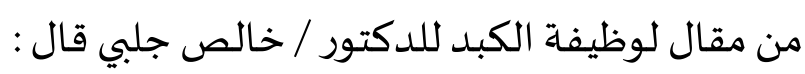

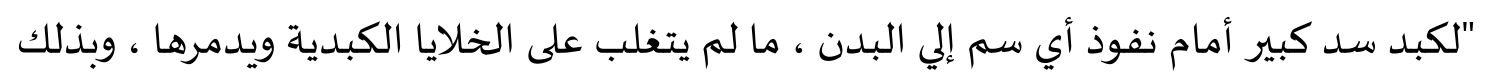

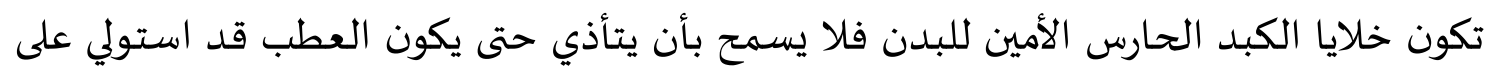

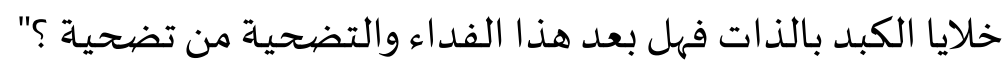

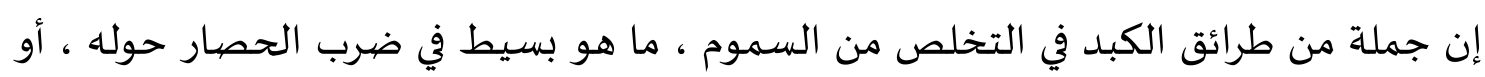

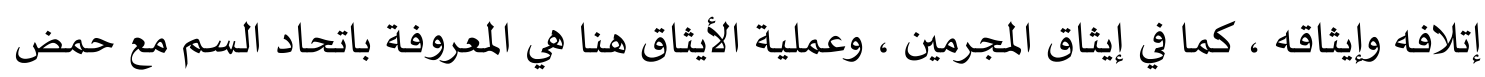

$$
\text { الكبريت ، أو حمض الفلوكورنيك . }
$$

وبهذه الطريقة يمكن نقل هذه المادة السامة بأمان من خلال المصرف المكان العام أي : القناة

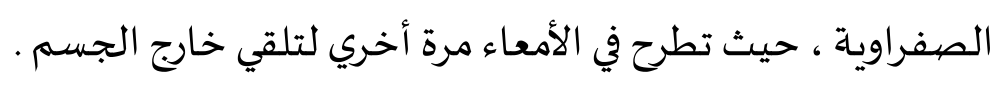

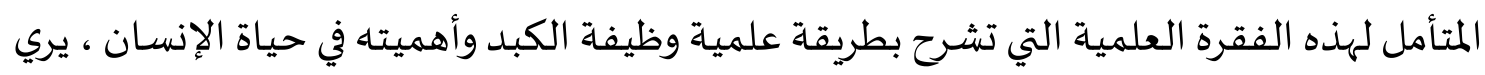

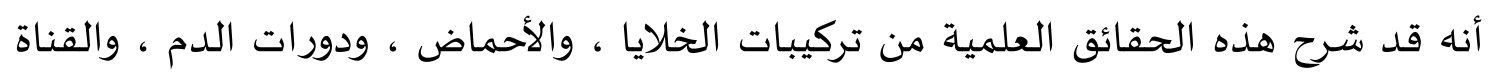

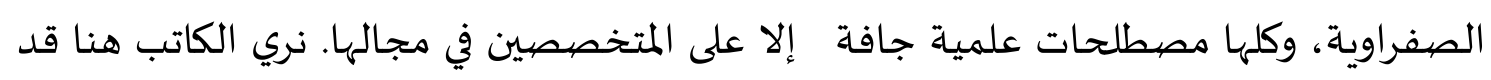

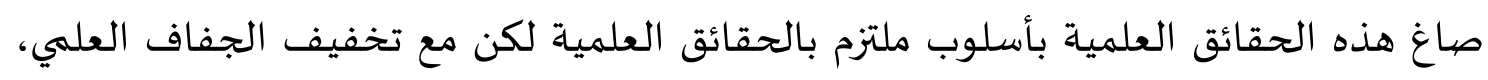

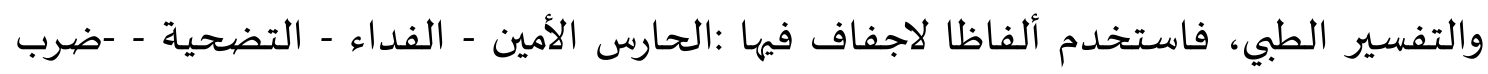

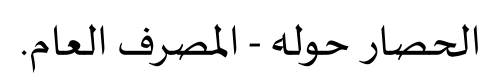

ومع احتفاظه بسلامة الحقائق العلمية فإنه قد قربها إلي الأذهان ووضحها بالصهور الخيالية ، مثل :

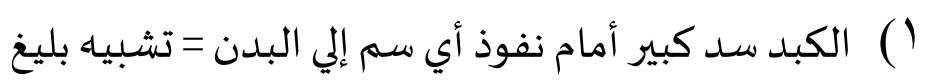

$$
\begin{aligned}
& \text { كما في إيثاق المجرمين = تشبيد (Y) }
\end{aligned}
$$

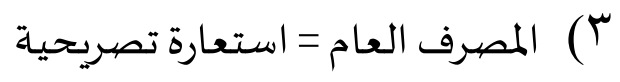


من هنا وجدنا أن هذه الفقرة تجمع بين موضوع وأهداف الأسلوب العملي ، وبين بعض سهولة ووضوح وخيال الأسلوب الأدبي ، فحق أن يسمي هذا الأسلوب العملي المتأدب . لأناه خليط من خصيائص الأسلوب العلمي ومن خصيائص الأسلوب الأدبي.

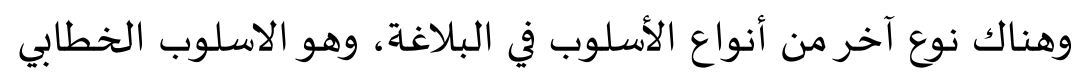

\section{ع) ( ) الأسلوب الخطابي}

في هذا الأسلوب تبرز قوة المعاني والألفاظ واضحة جلية، كما يتعمد هذا الأسلوب على الحجة والبرهان، وقوة العقل، وفي هذا الأسلوب يتحدث الخطيب إلى سامعياء لإثارة عزائمهم،

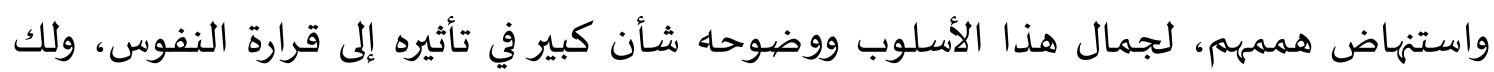
كان تنظر إلى خطبة الرسول ثلي الله عليه وسلم لجمع من الأنصيار، يقول: "يا معشر الأنصار ماقله بلغتني عنكم، ووجدة وجدتموها في أنفسكم ... والذي نفس محمد بلدي بيده

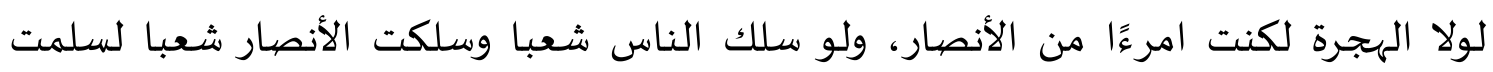
شعب الأنصار- اللهم ارحم الأنصار، وأبناء الأنصار"، قال الراوي فبكي القوم حتى أخضلوا

لحاهم وقالة رضينا برسول الله صلى الله عليه وسلم قسما وحظاً فانصرف رسول الله وتفرقوا. ومما يزيد في تأثير هذا الأسلوب، منزلة الخطيب في نفوس سامعياه، وسطوع حجتها،

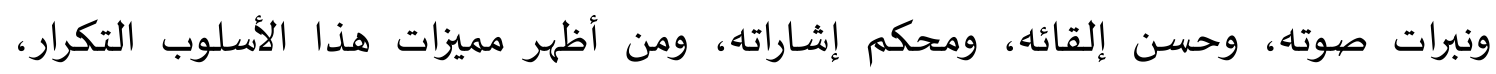
واستعمال المترادفات وضرب الأمثال، واختيار الكلمات الجزلة ذات التهات الرنين والإيقاع الصوتي، والجرس الموسيقى، ويحسن فياه- كذلك أن تتعاقب ضروب التعبير - من إخبار، إلى استفهام، إلى تعجب، إلى استنكار، وأن تكون مواطن الوقف وسئ كافية شافية. قال دكتور الإمام علي في كتابه "روائع نهج البلاغة" إن الأسلوب يتعلق بالعبقربة الخطابياة، مثل ما فعله علي بن أبي طالب حيث أنه من الذوق الفني أو الحسي الجمالي. وتتميز

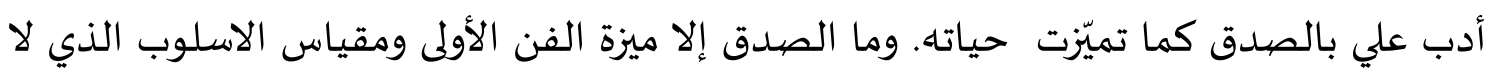
يخادع.

ومعروف أن لم تجتمع لأديب عربي كما اجتمعت لعلي ين أبي طالب، فإنشـاؤه مثل أعلى لهذه البلاغة بعد القرآن. فأسلوب علي صريح كقلبه وذهنه، صيادق كطويته، فلا عجب أن يكون نهجا للبلاغة.

وما سبق ذكره هو نهج خاص في الكتابة والتعبير عن الأفكار، وهناك نتوع أساليب

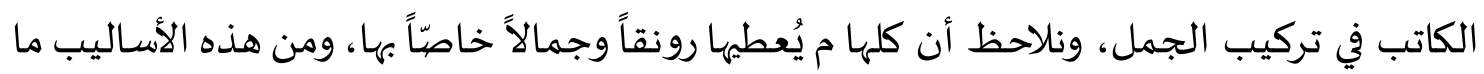
يأتي : 
أ) أسلوب النداء :يُعرف النّداء بأنّاه توجيه الكلام للمُحخاطَب. المثال: يا محمد لا تركض، أيا أحمد لا تفعل هذا ب) أسلوب الاستغاثة :الاستغاثة هي نداء شخص لمُسـاعدة غيره عن طريق استخدام حرف النداء. المثال: يا لمحمدِ لغيثب، بمعنى نداء محمد لإغاثة غيث ج) أسلوب الأمر، ويكثر هذا الأسلوب في القرآن الكريم، ومن الأمثلة عليه قولهه تعالى :فَإِذَا قُضِيَتِِّ

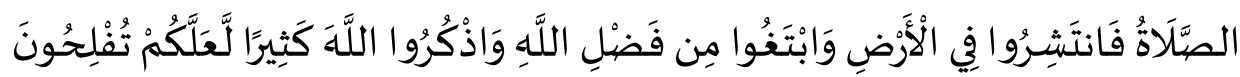

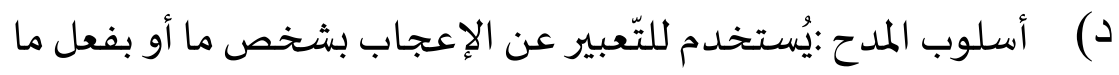
ه) أسلوب الذمّ :للتّعبير عن عدم الإعجاب بشخص ما أو فعل ما، وهو عكس المدح، ومن مأن

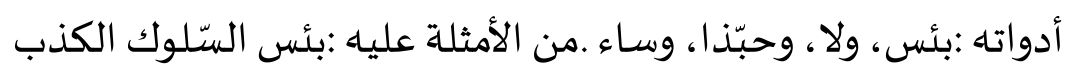

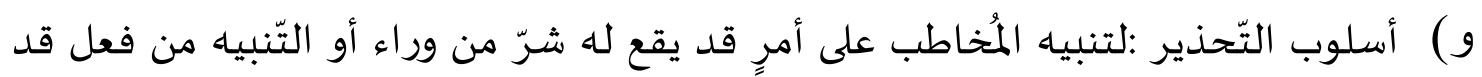

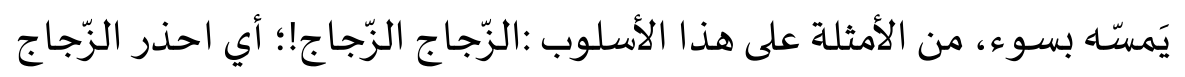

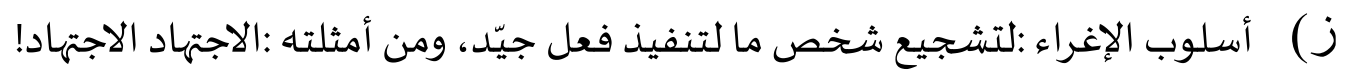

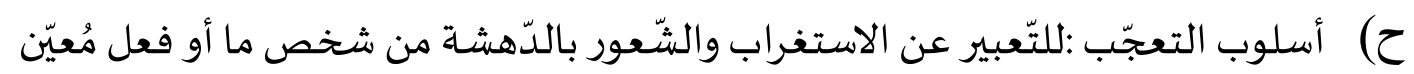
ط) أسلوب النُّدبة :وهو أسلوب البكاء والنّدب على الميّت وذكر خصياله الجيّدة .ومن الأمثلة عليه :

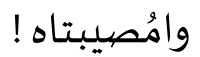

ي) أسلوب القَسَمَ :لتأكيد المعلومة، ومدحاولة إقناع المُخاطَب بها، ومعناه الحلف واليمن .

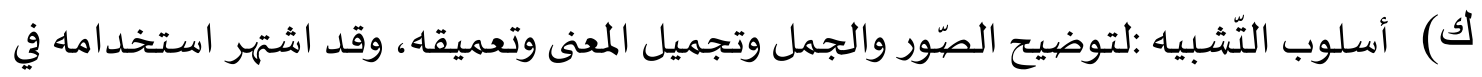

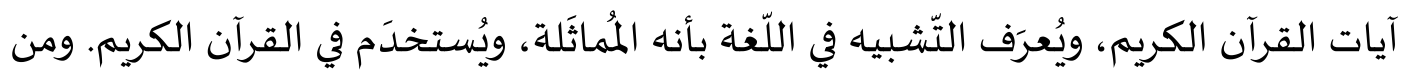

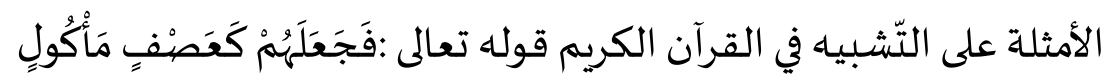

الخاتمة

قضايا الأسلوب لا تخفى عن الناس ولا يمكن للغويين أن يجهلوا أو يتجاهلوا ما وجد في هذا الميدان منذ مطلع القرن العشرين. حيث أن الأسلوب كان موجودا منذ زمن أرسطو وهو

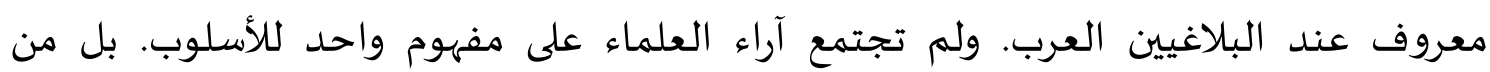
المعروف بين الناس الكثيرين أن الأسلوب يعنى طريقة التعبير عن الافكار، وقد تنوّعت الأساليب تنوّع اللامحدود. 
Ahmad Darwis. (2010). Dirasatu Al uslub Baina Al Mu'ashirah wa At Turast. Ad Damam: Maktabah Al Mutanaby

Al imam Ali. (d.t). Rawai'u Nahj Al Balaghah. Al Qahirah: Daar Asy Syuruq

Al Mukhtar Karim. (2006). Al Uslub wa Al Ihsha. Tunis: Mansyurat kuliyah Al Ulum Al Insaniyah wa Al Ijtima'iyah

Muhammad Abdullah Jabr. (1988). Al Uslub wa An Nahwu - Dirasah Tathbiqiyah Fii 'Alaqat Al Khashaish Al Uslubiyah Biba'dhi Adzawahir An Nahwiyah. Al Qahirah: Daar Ad Da'wah

'Ayasyir. (1994). Al Uslubiyah. Halb: Daar Al Hasub li Ath Thibaah

Abdu As Salam Al Musdy. (1982). Al Uslubiyah wa Al Uslub. Tarabils: Ad Daar Al Arabiyah Li Al Kitab

Muhammad Abdul Mun'im Khafaajiy wa Muhammad As Sa'dy Farhadad wa Abdul Azis Syariif. (1992). Al Uslubiyah ... wa Al Bayan Al Araby. Al Qahirah: Ad Daar Al Mishriyah Al Lubnaniyah

Yasir Abdul Muthalib Ahmad. Al Uslub wa Al Uslubiyah Syarh Al Uslub Al 'Ilmy wa Al Uslub Al Adaby. Usturji'a min https://www.modars1.com/t41564-topic

Al Uslub- Al 'Ilmy- Al Adaby- Al 'Ilmy Al Mutaaddib. (2012). Usturji'a minhttp://alanguage.ahlamontada.org/t56-topic 